\title{
Posmodernisme: Dampak dan Penerapannya pada Studi Islam
}

\author{
Abdul Mukti Ro'uf \\ Institut Agama Islam Negeri Pontianak \\ muktirouf@yahoo.com
}

Abstract: This paper focus on dialogue with postmodernism and religion while looking at some of the core ideas of postmodernism and the possibility of making it a reading tool for Islam, precisely for the benefit of Islamic studies, in contemporary society with its various implications. With the descriptive-analysis method this paper proves two things. First, that postmodernism as a movement of thought is not in direct contact with Islam. It is a response to the doctrine of modernism and traditional Christian doctrine. His criticism of religion is addressed to European Christians. However, the impact of his dissolution of value doctrine becomes nihilism, has disrupted the theological beliefs of religions, including Islam especially in the case of the spread of atheisticinclined ideology. Secondly, as a critical philosophy, postmodernism contributes a deconstruction method to dismantle the establishment and the absoluteness of thought. In Islamic studies, the deconstructive approach is widely used by contemporary Islamic thinkers.

Abstrak: $\quad$ Tulisan berkonsentrasi untuk mendialogkan postmodernisme dan agama sambil melihat beberapa gagasan inti posmodernisme dan kemungkinan menjadikannya sebagai alat baca bagi Islam, tepatnya bagi kepentingan studi Islam, dalam masyarakat kontemporer dengan berbagai implikasinya. Dengan metode analisis-deskriptif tulisan ini membuktikan dua hal. Pertama, bahwa posmodernisme sebagai gerakan pemikiran tidak bersentuhan langsung dengan Islam. Ia merupakan respon terhadap doktrin modernisme dan doktrin agama tradisional, Kristen. Kritiknya terhadap agama dialamatkan kepada Kristen 
Eropa. Namun demikian, dampak atas doktrinnya tentang penghapusan nilai (dissolution of value) menjadi nihilisme, telah mengganggu keyakinan teologis agama-agama, termasuk Islam terutama dalam hal penyebaran paham yang cenderung atheistik. Kedua, sebagai filsafat kritis, posmodernisme menyumbangkan metode dekonstruksi untuk membongkar kemapanan dan absolusitas pemikiran. Dalam studi Islam, pendekatan dekonstruktif banyak digunakan oleh pemikir Islam kontemporer.

Kata kunci: Post Modernisme, Pemikiran Islam,

\section{A. Pendahuluan}

Apa yang hendak dikatakan pada penggandengan istilah 'Islam' dan 'posmodernisme'1 dalam tema yang akan didiskusikan dalam tulisan ini?, dimana keduanya berdiri, dan untuk kepentingan apa keduanya dihubungkan? Apakah Islam sebagai suatu sistem nilai akan diuji oleh posmodernisme sebagai paradigma berfikir, ataukah Islam, sebagai kredo teologis akan digunakan sebagai alat baca (point of view) atas posmodernisme sebagai paradigma berfikir? Ataukah akan menempuh kemungkinan lain, yaitu mendialogkan keduanya untuk kepentingan eksistensi Islam dalam dunia yang sedang berubah dimana posmodernisme, ${ }^{2}$ dalam hal-hal tertentu telah

1 Istilah 'postmodern' atau 'postmodernism' sebagai diskursus filsafat pertama kali dikenalkan dan dilembagakan oleh filsuf Perancis Jean-Francois Lyotard (1924-1998) dalam karyanya, La Condition postmoderene: Rapport Sur Savior (1979) yang dalam versi Inggrisnya berjudul, The Postmodern Condition: A Report on Knowledge. Gagasan inti postmodern dalam konteks Lyotard kira-kira adalah bahwa ilmu pengetahuan dalam masyarakat industri maju akibat pengaruh teknologi baru telah berubah. Sehingga teknologi informasi tersebut dengan prinsip kesatuan ontologis yang selama ini mendasari ide dasar filsafat modern, sudah tidak lagi relevan dengan realitas kontemporer. Prinsip homologi (kesatuan ontologis) tersebut akan bergeser seiring dengan pengaruh dahsyatnya teknologi informasi. Untuk itu, prinsip tersebut harus didelegitimasi oleh paralogi atau ide pluralis. Tujuannya agar kekuasaan, termasuk kekuasaan oleh ilmu pengetahuan tidak lagi jatuh pada sistem totaliter. Totaliter biasanya bersifat hegemonik dan pro status quo, karenanya realitas tersebut harus dideligitimasi, agar tidak memberangus munculnya kebenarankebenaran, bukan sekedar kebenaran tunggal n.d. lihat; Jean-Francois Lyotard, Postmodern Condition: A Report on Knowledge (Manchester: Manchester University Press, 1984); Dalam kaitannya dengan diskursus keislaman lihat; Roxanne L. Euben Source, Premodern, Antimodern or Postmodern? Islamic and Western Critiques of Modernity" (The Review of Politics, 2014), http://www.jstor.org/stable/1408547.

2 Posmodernisme sering dibedakan dengan posmodernitas sebagaimana modernisme sering dibedakan dengan modernitas. Modernitas dan posmodernitas 
menjungkirbalikkan pandangan hidup saudara tuanya, modernisme, juga agama. Meskipun pada saat yang sama, ia adalah kelanjutan tak terpisahkan dari modernisme itu sendiri.

Dengan metode analitis deskriptif terhadap beberapa tokoh, Tulisan ini hanya akan berkonsentrasi pada kemungkinan ketiga, yaitu bagaimana mendialogkan keduanya sambil melihat beberapa gagasan inti posmodernisme dan kemungkinan menjadikannya sebagai alat baca bagi Islam, tepatnya bagi kepentingan studi Islam, dalam masyarakat kontemporer dengan berbagai implikasinya. ${ }^{3}$ Menakar posmodernisme sebagai alat baca ini menjadi penting dinataranya karena beberapa alasan mendasar yaitu adanya kecurigaan yang datang dari keduanya. Kaum agamawan (Islam) — karena pendirian posmodernisme tentang kebenaran relatif ${ }^{4}$ - khawatir akan terjadinya distorsi terhadap nilai-nilai keyakinan keagamaan yang ajeg dan terwahyukan. Implikasi lebih jauh, paradigma posmodernisme dapat

lebih menekankan pada struktur masyarakat. Sedangkan modernisme dan atau posmodernisme lebih menekankan pada struktur diskursus. Modernitas merupakan sebuatan bagi sebuah masa setelah masa abad pertengahan Eropa yang kemudian menghasilkan beberapa gugus gagasan yang hidup di dalamnya seperti kapitalisme, humanisme, dan rasionalisme. Begitu juga dengan posmodernitas yang menggambarkan suatu struktur masyarakat posindustri dimana konstruksi ekonomi mereka bergeser dari manufaktur ke jasa atau industri informasi. Singkatnya, akhiran -isme menggambarkan pola gugusan pemikiran pada saat itu sedangkan akhiran -itas menggambarkan realitas sosial pada saat itu. Tentang pembedaan defenisi, lihat lebih lanjut dalam, n.d.; George Ritzer, Postmodern Social Theory (United States America, 1976), 5-6; Akhyar Yusuf Lubis, Postmodernisme, Teori Dan Praktek (Jakarta: Rajawali Press, 2014), 9-13; James Trilling, "A Modernist's Critique of Postmodernism Vol. 9, No. 3 (Spring, 1996), Pp. 353-37," International Journal of Politics, Culture, and Society, 3, 9 (1996), http://www.jstor.org/stable/20019842. Diakses; Jürgen Habermas and Seyla Ben-Habib, “'Modernity versus Postmodernity', New German Critique," Winter, special Issue on Modernism, no. 22 (1981): 3-14.

${ }^{3}$ Studi mengenai hubungan antara agama dan psotmodernisme telah banyak dilakukan. Baik di kalangan filosof, sosiolog, maupun para pemikir keagamaan. Diantaranya dapat dilihat dalam karya-karya: N.d.; Akbar S Ahmed, Postmodernism and Islam: Predicament and Promise. (London \& New York: Routledge, 1992); Ernest Gellner, Postmodernism, Reason and Religion. (London: Routledge, 1992); David Griffin, God and Religion in Postmodern World (Albany: N.Y. State University of New York Press, 1989); Huston Smith, Beyond The Post-Modern Mind (Wheaton, Illinois, USA: The Theosophical Publishing House, 1989).

${ }^{4}$ Mengenai klaim bahwa prinsip kebenaran menjadi serba relatif, partikular, dan lokal, kaum posmodernis mengagungkan makna sebgai segalanya: "everything is meaning, and meaning is everything, and hermeneutics is its prophet". lihat; Gellner, Postmodernism, Reason and Religion., 24. 
menggeser dan menggusur eksistensi agama dalam masyarakat kontemporer. ${ }^{5}$ Sementara kaum posmodernisme, dalam berbagai kritiknya, tidak melihat masa depan agama bagi masyarakat yang terkomputerisasi. ${ }^{6}$

\section{B. Doktrin Posmodernisme}

Secara umum, periodisasi pemikiran filsafat terbagi tiga, yaitu pada masa Yunani kuno yang didominasi oleh rasionalisme, abad tengah didominasi agama Kristen dan filsafat abad modern didominasi oleh rasionalisme. Lantas muncul jenis filsafat baru yaitu filsafat kontemporer (contemporary philosophy). Periode keempat ini disebut filsafat pasca modern (postmodern philosophy), juga dikenal dengan sebutan filsafat postmo. Problematika dunia filsafat kontemporer sering dikatakan masuk dalam era postmodern meliputi beberapa persoalan besar seperti klaim bahwa filsafat telah berakhir, rasionalitas tunggal, universal tunggal dan epistemologi tunggal tidak mungkin dan tidak perlu lagi. ${ }^{7}$

Sejarah dan doktrin posmodernisme tidak terlepas dari sejarah dan doktrin modernisme. Sebab, dalam alur sejarah pemikiran, posmodernisme adalah reaksi atas capaian-capaian dari modernisme

5 Berbagai kekhawatiran itu dapat dimengerti karena alasan beberapa pernyataan sinis dari para penyokong posmodernisme terhadap agama. Misalnya dapat dilihat dalam karyanya Finkielkraut dalam bukunya The Defeat of the Mind yang menggambarkan kondisi agama pada era modern bahwa Tuhan bukan lagi Zat Yang Maha Kuasa, tapi merupakan akal kolektif. Lihat; Finkielkraut, The Defeat of the Mind (New York: Columbia University Press, 1995), 18; Hal senada pernah dikemukakan oleh Michel Foucault sebagaimana dikutip David Owen yang mengatakan bahwa Most of us no longer believe that ethic is founded in religion. (kebanyakan kita tidak lagi percaya bahwa etika itu berdasarkan pada agama). Lihat; David Owen, Maturity and Modernity (London: Routledge, 1994), 200.

${ }^{6}$ Ada dua orientasi Pascamodernisme, yaitu Pascamodernisme skeptik dan pascamodernisme afirmatif. Penganut Pascamodernisme skeptis menegaskan bahwa setelah modernisme yang ada hanyalah pluralisme radikal, artinya tidak ada kebenaran tunggal yang berperan sebagai pusat. Tokoh-tokoh yang dipandang sebagai pendukung Pascamodernisme skeptis ini antara lain: Michel Foucault, Roland Barthes, Derrida, Richard Rorty, dan Lyotard. Pascamodernisme afirmatif menolak tendensi nihilisme, bagi mereka pluralisme tidak serta merta meniscayakan nihilisme dan menyangkal ide tentang kebenaran, namun lebih meletakkan kebenaran dalam konteks lokal dan mini naratif. N.d.; Ahmad Sahal, Agama Dan Tantangan Posmodernisme (Jakarta: Islamika, 1993), 66-67 lihat.

${ }^{7}$ Bambang Sugiharto, Postmodernisme Tantangan Bagi Filsafat, n.d., 18. 
itu sendiri. ${ }^{8}$ Dan pada saat yang sama adalah modernisme itu sendiri. Seperti pandangan Jurgen Habermas ${ }^{9}$ yang menggambarkan bahwa posmodernisme menjadi ahistoris jika ia tercerabut dari modernisme. Menurutnya, konsep posmodernitas, jika ia mengaku berdiri sendiri, adalah konsep yang abstrak dan ahistoris mengenai "modernitas" yang dikembangkan oleh ilmu-ilmu sosial Barat. ${ }^{10}$ Ia bertahan bahwa apa yang disebut dengan posmodernisme itu adalah modernisme itu sendiri. ${ }^{11}$

Di sisi lain, para pencetus posmodernisme mengaku bahwa mereka telah mencapai kesepakatan bahwa universalisme modernisme telah berakhir. Mereka menggantikannya dengan yang partikular dan lokal. Postmodernisme menolak penekanan kepada penemuan ilmiah melalui metode sains, yang merupakan fondasi intelektual dari modernisme untuk menciptakan dunia yang lebih baik. Posmoderenisme menolak apa yang disebut sebagai 'metanarasi' 12

8 Diantara ciri yang membedakan antara modernisme dan posmodernisme dapat dilihat dalam 'kondisi pengetahuan' seperti yang dikenalkan oleh filsuf Perancis kontemporer JF Lyotard (1924-1998). Selama ini, modernisme mengklaim bahwa pengetahuan ilmiah atau sains sebagai satu-satunya jenis pengetahuan yang valid. Bagi Lyotard, klaim seperti itu hanyalah permainan bahasa. Karena itu, ia menawarkan untuk tidak percaya terhadap metanarasi yang dikembangkan modernisme. Sehingga, posmodernisme dapat dimengerti sebagai ketidakpercayaan terhadap metanarasi ('incredulity towards metanarratives'). Lihat n.d.; Lyotard, Postmodern Condition: A Report on Knowledge, xxiii.

${ }^{9}$ Jurgen Habermas adalah seorang filsuf dan sosiolog dari Jerman. Ia adalah generasi kedua dari Mazhab Frankfurt. Jurgen Habermas adalah penerus dari Teori Kritis yang ditawarkan oleh para pendahulunya (Max Horkheimer, Theodor Adorno, dan Herbert Marcuse). Lahir 18 Juni 1929 di kota Dusseldorf, Jerman. Karyanya yang relevan dalam masalah modernitas dan postmodernitas adalah, The Philosophical Discourse of Modernity. N.d.

${ }^{10}$ Pandangan 'sinis' Habermas terhadap para penganjur posmodernis yang 'menelanjangi' modernisme dapat dipahami karena baginya, sebagai orang yang pro pencerahan, berpendirian bahwa sebuah rasional itu tidak hanya mungkin, tetapi secara normative sedang dituju oleh segala bentuk masyarakat sejauh ilmu dan teknologi menjadi agen perubahan di dalamnya. N.d.; F Budi Hardiman, Filsafat Fragmentaris (Yogyakarta: Kanisius, 2007), 151.

${ }^{11}$ Jurgen Habermas, The Philosophical Discourse of Modernity (Blackwell Publisher, 1987), 3.

12 Narasi merupakan cara bagaimana dunia direpresentasikan ke dalam berbagai konsep, ide, gagasan, dan cerita. Narasi besar (grand narrative) atau metanarasi adalah ilmu pengetahuan yang melegitimasi dirinya sendiri lewat meta discourse dengan bersandar atas fondasi-fondasi seperti spirit, makna, subjek, 
Ciri khas posmodernisme adalah ketiadaan titik pusat yang mengontrol segala sesuatu. Meskipun posmodern dalam masyarakat bermacam-macam bentuknya, mereka sama-sama sepakat bahwa tidak ada fokus atau titik pusat. Tidak ada lagi standar umum yang dapat digunakan untuk mengukur, menilai atau mengevaluasi konsep-konsep dan gaya hidup tertentu. Tidak ada kekuasaan yang absah dan berlaku untuk semua. Titik pusat sudah bergeser, masyarakat seperti kumpulan barang- barang yang beraneka ragam. Unit-unit sosial yang lebih kecil hanya disatukan secara geografis.

Filsuf posmodern, Michel Foucault (1926-1984), menawarkan sebuah usulan nama bagi dunia tanpa titik pusat, yaitu "heterotopia." 13 istilah Foucault menggarisbawahi perubahan besar yang sedang berlangsung. Keyakinan Pencerahan akan suatu kemajuan yang terusmenerus melahirkan visi modernisme. ${ }^{14}$ Mimpi modernisme tentang bangunan masyarakat yang sempurna, berkeadilan, dan damai telah dibuang dan dianggap sebagai mimpi kosong. Mereka hanya menawarkan keanekaragaman yang tak terhitung banyaknya, "multiverse" telah menggantikan model "universe" dari modernisme. ${ }^{15}$

Sistem nilai penting lain yang dikumandangkan oleh posmodernisme adalah masalah nihilisme ${ }^{16}$ seperti yang dikembangkan

rasionalitas, atau logos. Nah, filsafat modern dibangun di atas fondasi-fondasi seperti itu.

${ }^{13}$ Istilah ini hendak menegaskan bahwa kebenaran (pengetahuan) tidak bisa bermuara pada satu titik yang disebut sebagai 'kebenaran ilmiah' seperti yang diyakini oleh modernisme. Dalam era modern paradigma berfikirnya selalu bermuara pada materialistik, sebab yang dapat terukur oleh kekuatan atau jangkauan rasio adalah halhal yang nyata dan faktual yang bersifat materi. Dengan demikian modernisasi lebih cenderung untuk melegitimasikan tiap bentuk pengetahuan melalui semacam "meta wacana" atau "narasi besar" seperti kemajuan, kebebasan berfikir, emansipasi, dan sebagainya. Karena, dengan bgitu, kebenaran dimonopoli oleh titik yang menurut Lyotard telah menghilangkan narasi-narasi tradisonal yang lain. Padahal, 'kebenaran ilmiah' tidak memiliki legitimasi yang kuat. Satu-satunya legitimiasinya adalah kesepakatan 'kaum ilmiah' dan menurut Lyotard-dengan meminjam konsep bahasanya Wittgenstein - kebenaran ilmiah hanyalah permainan bahasa semata. Lyotard, Postmodern Condition: A Report on Knowledge, 9-10.

14 Michel Foucault, "Of Other Spaces, Heterotopias," n.d., http://foucault.info/documents/heterotopia/foucault.heterotopia.en.html.

${ }^{15}$ Trilling, “A Modernist's Critique of Postmodernism Vol. 9, No. 3 (Spring, 1996), Pp. 353-37.”

${ }^{16}$ Nihilisme adalah suatu cara untuk memosisikan manusia dalam wilayah tak bertuan atau kekosongan terhadap segala macam nilai, sehingga eksistensi manusia dapat diekspresikan secara bebas tanpa intervensi tentang gagasan 
oleh penentang modernisme paling kritis dan penggagas posmodernisme paling berpengaruh, Friedrich Wilhelm Nietzsche (1844-25 August 1900). ${ }^{17}$ Pandangan ini tidak hanya menyerang pendirian modernisme tentang pandangan bahwa hanya objektivitas sains-lah yang dapat menghantarkan kebahagiaan manusia, tetapi juga menohok pendirian religuisitas gereja yang memiliki pandangan tentang otoritas kebenaran hanya ada di tangan Tuhan. Dengan nihilismenya Nietzsche, jargon modernisme dan keyakinan keagamaan telah rontok.

Jagoan posmodernis lain, Heidegger (1889-1976), memiliki pandangan yang senyawa dengan Nietzsche yang mengatakan bahwa nihilisme sebagai "proses pengosongan yang bermuara pada sesuatu "yang tak bersisa". Dalam pandangan Nietzsche proses nihilisme adalah devaluasi nilai tertinggi: "What does nihilism mean? That the highest values devaluate themselves. The aim is lacking; "why?" finds no answer". ${ }^{18}$

Prinsip ini membawa pada kesimpulan atas doktrin "kematian Tuhan". Dalam pandangan Heideger nihilisme menunjukkan penghapusan Being (konsep 'ada") dengan sedemikian rupa sehingga menjelma menjadi nilai. Di sini realitas tidak lagi dipahami dalam bentuk suatu susunan dimana sang pencipta berada pada puncak hirarki yang absolut. Keduanya menuju suatu titik dimana manusia tidak lagi berpegang pada struktur nilai. Nilai tidak lagi mempunyai makna. Suatu konsep tentang apapun tidak lagi berdasarkan pada sesuatu yang metafisis, religius ataupun mengandung unsur ketuhanan (divine).

Beberapa doktrin inti dari postmodern dengan demikian dapat disarikan antara lain, pertama, Penolakan atas keuniversalan suatu pemikiran. Yang ada adalah relativitas dari eksistensi plural. cara berpikir "totalizing" harus digeser kepada cara berpikir "pluralistic

ketuhanan. Karena dengan adanya kekosongan dan tiadanya tujuan yang dipatokan secara jelas, maka seluruh potensi fundamen manusia akan terekspose dengan baik demi terciptanya manusia unggul yang memiliki kualitas brilliant yang dalam istilah Nietzsche disebut sebagau ubermench. Lihat n.d.; lihat Nietzsche, The Will To Power (New York: Random House, 1968), 8-9.

${ }^{17}$ Betapa pentingnya posisi Nietzsche dalam pemikiran posmodernisme, Jurgen Habermas menulis sub titel bukunya yang penting, The Philosophical Discourse of Modernity dengan judul, The Entery into Postmodernity: Nietzsche as a Turning Point. N.d.; Habermas, The Philosophical Discourse of Modernity, vi.

${ }^{18}$ Nietzsche, The Will To Power, 9. 
and open democracy" dalam segala aspek kehidupan, termasuk berkaitan dengan agama. Kedua, menekankan akan terjadinya pergolakan pada identitas personal maupun sosial secara terusmenerus, sebagai ganti dari permanenitas. Jika pemikiran manusia selalu terjadi perubahan, maka perubahan tadi secara otomatis akan dapat menjadi penggerak untuk perubahan dalam disiplin lain. Pandangan ini menolak segala bentuk konsep fundamental bersifat universal yang memiliki nilai sakralitas dan yang menjadi tumpuan konsep-konsep lainnya. Ketiga, pengingkaran atas semua jenis ideologi termasuk ideologi agama. Keempat, Pengingkaran atas setiap eksistensi obyektif dan permanen. Atas dasar pemikiran relativisme yang diyakini. Kelima, kritis atas semua jenis epistemologi. Kritik tajam secara terbuka merupakan asas pemikiran filsafat postmodernisme. Pemikiran ataupun setiap asumsi yang bersifat prinsip yang berkaitan dengan keuniversalan, sebab akibat, kepastian dam sejenisnya akan diingkari.

\section{Kritik posmodernisme atas agama}

Tata pikir dan tata nilai yang dirumuskan dan dikembangkan posmodernisme $^{19}$ memang dapat mengganggu eksistensi agama tradisional. Ia menyerang keajegan modernisme dan agama sekaligus. ${ }^{20}$ Lantas persoalannya, apakah doktrin modernisme dan agama mudah rapuh dengan dekonstruksi yang dikembangkan oleh posmodernisme ataukah justru makin kuat eksistensinya karena kritik tajam yang datang dari posmodernisme. Atau, ketiganya tanpa sadar saling 'berkoalisi' untuk tujuan saling menguatkan satu sama lain.

Pemahaman agama dalam kacamata Barat posmodern memiliki motivasinya sendiri. Karenanya diperlukan pembacaan elaboratif atas berbagai pemikiran posmodernisme itu. Bahkan, untuk memahaminya memerlukan penelusuran atas pandangan modernisme

${ }^{19}$ Untuk memahami doktrin inti posmodernisme, mau tidak mau harus menelaah beberpa konsep inti yang dirumuskan oleh para penganjurnya. Beberapa diantaranya dapat ditelusuri pada pemikiran Nietzsche dan para ahli warisnya seperti, Heidegger, Derrida, Foucault, Bataile, Baudrillard.

20 Secara umum, karakteristik posmodernisme dapat dikatakan bahwa pemikiran tentang agama telah mengalami perubahan, yaitu dari aspek sifatnya. Pemikiran modern-posmodern mereduksi teologi menjadi antropologi. 
tentang agama. ${ }^{21}$ Maka, menela'ah jalan pikiran para 'juru bicara' posmodernisme yang berkaitan dengan masalah-masalah keagamaan relevan untuk didiskusikan.

\section{Membaca Nietzsche (1844-1900)}

Nietzsche seperti membawa palu godam. Filsafatnya memukul dengan sangat keras segala keyakinan, dogma yang tak tergoyahkan. Ia mengkritik seluruh kemapanan baik yang dibawa oleh modernisme maupun agama. Iapun, lantas menjadi sasaran kritik kaum agama atas beberapa deklarasi filosofisinya yang menyengat keyakinan teologis. Mengapa Nietzsche begitu dibenci kaum agama/teolog? Ini terkait dengan beberapa doktrin filosofisnya tentang: nihilisme, Übermensch (adi manusia), wille zur Macht (The will to Power, Kehendak untuk Berkuasa), dan die ewige widerkehr des gleichen (The Eternal Recurence of The Same). Bagi Nietzsche, tujuan pengetahuan bukanlah untuk menangkap kebenaran absolut yang ada pada dirinya, melainkan untuk menundukan sesuatu. Nietzsche tidak meyakini adanya kebenaran yang absolut, karena itu hanya merupakan fiksi yang seseorang buat karena interpretasi terkait dengan kebutuhan terbatas dan interpretasi pasti bersudut pandang. Oleh karena itu kebenaran bersifat perspektifal, tergantung perspektif penafsir: "tidak ada fakta, yang ada hanya tafsir", begitu tegas Nietzsche.

Pandangan Nietzsche tentang nihilisme ${ }^{22}$ telah menghancurkan pandangan keagamaan pada umumnya. ${ }^{23}$ Nietzsche mengkritik konsep Tuhan dalam agama tradisional yang abstrak dengan pernyataannya, God ist tot ("Tuhan telah mati"). Pernyataan ini adalah pernyataan filosofis sebagai kritik terhadap pandangan teologis Kristen tentang Tuhan yang tidak dapat mendengar, dan jikapun Ia mendengar, tidak

${ }^{21}$ Akbar S. Ahmed, Postmodernisme and Islam: Predicament and Promise (London \& New York: Routledge, 1992), 6.

22 Nihilisme dalam konteks pemikiran Nietzche harus diletakkan dalam semangat posmodernisme, yaitu semangat penghapusan otoritas keagamaan tradisional dengan program penghapusan nilai (dissolution of value) dan penggusuran tendensi yang mengagungkan otoritas n.d.; Gianni Vattimo, The End of Modernity (Polity Press in Association with B. Blackwell, 1988), 167; Dalam karyanya Will to Power Nietzsche menggambarkan nihilisme sebagai situasi dimana "manusia berputar dari pusat ke arah titik X", artinya "nilai tertinggi mengalami devaluasi dengan sendirinya. Untuk melihat pendapatnya, n.d.; lihat Nietzsche, The Will to Power, 8-9.

${ }^{23}$ Konteks keagamaan yang dikritik Nietzsche adalah pandangan Kristen. N.d. 
tahu bagaimana untuk menolong. Tuhan juga tidak dapat menjadikan dirinya mudah dimengerti dan Ia sendiri juga kabur tentang diriNya dan tentang apa yang Ia maksud. Bagaimana memaknai deklarasi "kematian Tuhan" oleh Nietzche, pandangan penulis, ada tiga interpretasi yang memungkinkan untuk itu. Pertama, sebagai pandangan filosofis, Nietzche sedang mengkritik pandangan agama tradisional (Kristen) yang menyerahkan kekuatan kepada Tuhan yang abstrak dimana manusia tidak bisa merasakan kekuatannya. Di sini, di tangan Nietzche, kekuatan Tuhan tidak berdaya. Yang harus dikuatkan adalah kekuatan manusia. Karena itu bisa dikatagorikan sebagai pandangan atheistik dalam pengertian meniadakan 'the power of God' dalam kehidupan manusia. Baginya, konsepsi tentang Tuhan hanyalah konsepsi yang datang dari persepsi manusia, bukan datang dari langit. Kedua, Nietzche sedang 'mabuk' akan 'the power of human' dengan mengedealisasi konsep ubermench (uber: melampaui, mench: manusia). Maksudnya adalah makhluk yang melampaui (bukan menolak) tata nilai baku (baik-buruk, benar-salah). Watak ubermench adalah mencipta moral baru dan melampaui moral umum, terutama sistem moral yang dibentuk oleh modernisme dan agama tradisional, Kristen. Ketiga, Nietzche dalam hal-hal tertentu gagal-tentu saja dalam ukuran teologis-dalam memahami konsep ketuhanan. Sehingga, pemahamannya terjatuh hanya kepada "bahwa konsep Tuhan hanyalah persepsi manusia". Keberadaan Tuhan dan kekuatannya hanya ada dalam pikiran manusia. Memang, pernyataan filosofis tersebut terdengar atheistik, akan tetapi kalau dipahami lebih mendalam terkandung nilai spiritualistik yang luar biasa. ${ }^{24}$

2. Membaca Jacques Derrida (1930-2004) ${ }^{25}$

"Derrida itu menjengkelkan, tapi perlu", begitu judul yang ditulis Firmansyah Agus ketika memberikan pengantar terjemahan

${ }^{24}$ Ide "penyingkiran" Tuhan dari cara berpkir posmodern merupakan tren dari abad ke-20 sebagaimana digambarkan oleh Alfred North Whitehead dan Akber S. Ahmed. Ibid.; lihat Smith, Beyond The Post-Modern Mind, 8.

${ }^{25}$ Jacques Derrida lahir di Aljazair pada tangggal 15 Juli 1930. Pada tahun 1949 ia berpindah ke Perancis, di mana ia tinggal sampai akhir hayatnya. pemikirannya sangat dipengaruhi oleh filsuf Edmund Husserl dan ahli bahasa Ferdinand de Saussure. Lebih lanjut lihat David Mikics, Who Was Jacques Derrida? : An Intellectual Biography (New Heven \& London: Yale University Press, 1961), 3240; bandingkan dengan Mieke Bat and Hent de Vries, Counterpath Traveling with Jacques Derrida (Calivornia: Stanford University Press, 2004). 
buku Derrida, Off Spirit: Heidigger and the Question. ${ }^{26}$ Tokoh posmedrenis lain adalah Jacques Derrida. Di tangan Derrida, metode dekonstruksi ${ }^{27}$ yang berasal-usul dari Martin Heidigger menjadi lebih operasional ketika hendak diterapkan dalam membaca teks. ${ }^{28}$

Kegelisahan Derrida dialamatkan kepada sistem metafisika modernisme tentang konsep "ada" (being) sebagai kehadiran dan "logosentrisme" (percaya pada rasio). Metafisika kehadiran menjelaskan bahwa suatu konsep atau teori dapat dikatakan benar jika sudah mewakili "being" (ada). Sesuatu yang "ada" itu bisa terwakili oleh kata dan tanda. Derrida menolak pandangan tersebut. Baginya, kata, tanda, dan konsep bukanlah kenyataan yang menghadirkan "ada" melainkan hanya berupa "bekas" (trace). Baginya, sesuatu yang "ada" bersifat majemuk, tak berstruktur, dan tak bersistem, hingga tak bisa sekonyong-konyong dibenarkan melalui kata, tanda, dan konsep tunggal. Maka metafisika kehadiran harus dibongkar (dekonstruksi) untuk menemukan solusi atas permasalahan modernitas.

Dekonstruksi Derrida merupakan upaya meruntuhkan ambisi supermasi filsafat atas kehidupan publik. Dengan demikian, filsafat tidak lagi tampil sebagai proyek emansipatoris yang mengarahkan dunia publik. Karena dengan dekosntruksi kebenaran filsafat tidak lagi

${ }^{26}$ Firmansyah Agus, Dekonstruksi Spiritual, Merayakan Ragam Wajah Spiritual (Yogyakarta: Jalasutra, 2002), 23.

27 Istilah dekonstruksi (deconstruction) sendiri pada mulanya dipakai sebagai terjemahan dari term yang dipakai oleh Heidegger dalam salah satu bukunya Being and Time yang ditulis pada tahun 1972-an, yaitu destruksi (destruction). Heidegger menggunakan term destruksi ini sebagai upaya pelucutan atas bangunan pemikiran yang telah terbentuk sedemikian rupa. Destruksi di sini artinya pembongkaran (a freeing-up) atau pelucutan (a de-structuring). Walaupun begitu istilah destruction tidak dimaknai Heidegger sebagai penghancuran total (obliteration) yang tidak menyisakan apa-apa lagi. Destruksi yang membawa semangat pembongkaran dan pelucutan ini kemudian memberi inspirasi Jacques Derrida untuk menerapkan ide deconstruction-nya. Dalam kaitannya dengan pemahaman, teori dekonstruksi berkaitan dengan teknik membaca teks (a reading technique). Yaitu suatu teknik yang menjadikan teks itu 'bertarung dengan dirinya sendiri', atau teknik yang berupaya membuka fenomena makna yang tersembunyi di balik kata-kata, ide atau gagasan (words) yang terdapat pada setiap teks, namun tertutupi akibat "kepurapuraan makna" yang nampak secara literal dan melekat pada teks. N.d.; lihat Martin Heidigger, Being and Time (Oxford: Basil Blacwell, 1962).

${ }^{28}$ Di kemudian hari, metode ini sering digunakan oleh pemikir kontemporer Islam dalam membaca teks/tradisi Arab-Islam seperti yang akan disinggung dalam tulisan ini dengan menghadirkan contoh dalam kasus pemikiran Muhammad Arkoun dan Muhammad 'Ābid al-Jābirī.. 
merupakan representasi kebenaran dunia di luar sana. "every thing is tekxt and there is noting beyond the tekxt." Segala sesuatu adalah teks, kenyataan filsafat adalah kenyataan tekstual. ${ }^{29}$

Derrida menjelaskan dekonstruksi dengan kalimat negasi. Menurutnya dekonstruksi bukan suatu analisis dan bukan kritik, bukan suatu metode, bukan aksi maupun operasi. Singkatnya, dekonstruksi bukanlah suatu alat penyelesaian dari "suatu subjek individual atau kolektif yang berinisiatif dan menerapkannya pada suatu objek, teks, atau tema tertentu". Dekonstruksi adalah suatu peristiwa yang tidak menunggu pertimbangan, kesadaran, atau organisasi dari suatu subjek, atau bahkan modernitas.

Derrida mengadaptasi kata dekonstruksi dari kata destruksi dalam pemikiran Heidegger. Kata dekonstruksi bukan secara langsung terkait dengan kata destruksi melainkan terkait kata analisis yang secara etimologis berarti "untuk menunda"-sinonim dengan kata mendekonstruksi. Terdapat tiga poin penting dalam dekonstruksi Derrida, yaitu: pertama, dekonstruksi, seperti halnya perubahan terjadi terusmenerus, dan ini terjadi dengan cara yang berbeda untuk mempertahankan kehidupan; kedua, dekonstruksi terjadi dari dalam sistem-sistem yang hidup, termasuk bahasa dan teks; ketiga, dekonstruksi bukan suatu kata, alat, atau teknik yang digunakan dalam suatu kerja setelah fakta dan tanpa suatu subyek interpretasi.

Bagi Derrida, mengubah realitas berarti mengubah teks, dan teks itu sendiri adalah realitas kehidupan manusia. Untuk mengubah realitas, seseorang perlu terlebih dahulu memahami dan menggambarkan realitas. Ada keterkaitan yang mendalam antara menggambarkan (to describe) dan mengubah (to transform). Titik berangkat Derrida adalah teori tindakan tutur (speech act theory) yang banyak dikembangkan di dalam teori komunikasi maupun linguistik. Sebelum merumuskan pemikirannya sendiri secara orisinil, ia banyak mendalami teori tindakan tutur, terutama seperti yang dirumuskan oleh J.L Austin. Buku yang menjadi acuan utama Derrida adalah How to do Things with Words, karangan Austin. Menurut Austin setiap tindakan

${ }^{29}$ Abdul 'Dubbun' Hakim, “Diskursus Filosofis Modernitas, Debat Jurgen Habermas Dan Jacques Derrida," in Majalah Filsafat Diryakara, 2nd ed., vol. xxv (Jakarta: Seksi Publikasi Senat Mahasiswa, 2001), 63. 
berbicara manusia dapat diartikan dengan dua cara, yakni secara konstatif, atau secara performatif.

Dengan demikian Derrida tidak hanya menggambarkan maksud teks-teks yang dibacanya secara persis, tetapi juga mengubahnya menjadi teks yang memiliki makna baru. Dua konsep itu yakni deskripsi/penggambaran (description) dan transformasi (transformation) dapat digabungkan menjadi dekonstruksi (deconstruction). Sekilas konsep dekonstruksi ini tampak aneh dan kontradiktif. Bagaimana mungkin membaca secara tepat sekaligus mengembangkan makna teks dengan mengubahnya? Namun itulah yang kiranya dilakukan Derrida. Menurut penelitian Nicholas Royle, ${ }^{30}$ Derrida sendiri tidak begitu suka dengan kata tersebut. Konsep itu pun melepaskan diri dari Derrida, dan mulai menjadi sebuah paham, yakni sebuah isme. Sejak saat itu konsep dekonstruksi terus menjadi subyek perdebatan banyak pemikir lintas displin ilmu.

Royle bahkan berpendapat bahwa kita dapat memahami filsafat Derrida tanpa menggunakan konsep dekonstruksi sama sekali. Memang hal itu akan sangat sulit, namun bukan berarti tidak mungkin. Di dalam kamus filsafat dan kamus Bahasa Inggris, seperti dikutip oleh Royle, dekonstruksi didefinisikan sebagai suatu tindakan untuk mengubah konstruksi dari suatu benda. Di dalam kamus filsafat, dekonstruksi didefinisikan sebagai suatu strategi analisis yang dikaitkan dengan filsuf Perancis, Jacques Derrida, yang bertujuan untuk membuka pengandaian-pengandaian metafisis yang sebelumnya tidak dipertanyakan, serta membuka kontradiksi internal di dalam filsafat maupun teori-teori bahasa.

\section{Metode Dekonstruksi untuk Studi Islam}

Bisa jadi posmodernisme telah menggelisahkan sistem dan bangunan teologi karena sistem filsafatnya yang memukul sistem metafisika modernisme dan agama. Maka muncul pertanyaan, apakah ada pemikiran yang dikembangkan oleh posmodernisme yang bisa digunakan oleh agama (Islam) terutama untuk kepentingan studi Islam? Pemikiran posmodernisme mulai direspon oleh kaum agama n.d., 24 .

${ }^{30}$ Nicholas Royle, Jacques Derrida, (London \& New York, Routledge, 2003) 
dan peminat studi agama-agama dimulai oleh Harvey Cox $^{31}$ dengan kemunculan teologi pasca modern dan gerakan pembebasan yang didasari atas visi teologis. ${ }^{32}$

Dalam konteks studi Islam, pemikiran posmodernisme banyak dianut oleh para pemikir Islam kontemporer. Pemikir Islam asal Aljazair, Muhammad Arkoun adalah salah satunya. Pemikiran Arkoun merupakan perpaduan dari berbagai jenis perkembangan wacana ilmu yang digandrungi di Perancis seperti Derrida (Dekonstruksi gramatologi) $^{33}$, Lacan (psikologi) ${ }^{34}$, Barthes (semiologi) ${ }^{35}$, Foucault (epistemology), Poststrukturalisme ala Saussure (linguistik), Levi

${ }^{31}$ Harvey Cox pernah memprediksikan bahwa modernisme dan modernisasi, juga posmodernisme hanya akan menciptakan secular city; ia adalah lonceng kematian bagi agama. Menurut teori ini, semakin modern suatu masyarakat, semakin jauh pula mereka dari agama; agama diprediksikan tidak akan pernah bangkit lagi dalam arus modernisasi dan sekularisasi yang tidak terbendung. Baca Harvey Cox, Religion and the Secular City: Toward a Postmodernism Theology (New York: Simon and Shuster, 1984).

32 lihat Cox, Religion and the Secular City: Toward a Postmodernism Theology, 13; bandingkan dengan David Ray Griffin and Huston Smith, Primordial Truth and Postmodern Theology (New York: State University of New York Press, 1989), 25.

33 Makna dekonstruksi secara umum adalah tindakan subjek yang membongkar suatu objek yang tersusun dari berbagai unsur yang memang layak dibongkar. ihat Christoper Norris, Membongkar Teori Dekonstruksi Jacques Derrida (Yogyakarta: Ar-Ruzz Media, 2008), 68.

${ }^{34}$ Jacques Lacan (1901-1981) adalah seorang psikoanalisis Prancis yang paling terkmuka. Dia mengembangkan psikoanalisis menggunakan berbagai gagasan dalam antropologi dan linguistik strukturalisme. Ia mereinterpretasikan Freud dengan menggunakan teori strukturalisme dan poststrukturalisme. Dengan teori psikoanalisisnya, Lacan memberi banyak kontribusi bagi cultural studies dan kritik kebudayaan, misalnya seperti teori citra cermin, hasrat atau postulat "ketaksadaran itu terstruktur seperti bahasa." lihat Mark Bracher and Jacques Lacan, Diskursus, Dan Perubahan Sosial: Pengantar Kritik Budaya Psikoanalisis (Yogyakarta: Jalasutra, 2009).

${ }^{35}$ Roland Barthes (1915-1980) menggunakan teori siginifiant-signifié dan muncul dengan teori mengenai konotasi. Barthes menekankan teorinya pada mitos dan pada masyarakat budaya tertentu (bukan individual). Ia mengemukakan bahwa semua hal yang dianggap wajar di dalam suatu masyarakat adalah hasil dari proses konotasi. Ia menekankanpada penandaan. Barthes menggunakan istilah expression (bentuk, ekspresi, untuk signifiant) dan contenu (isi, untuk signifiè). Secara teoritis bahasa sebagai sistem memang statis, misalnya meja hijau memang berarti meja yang berwarna hijau. Ini disebutnya bahasa sebagai first order. Namun bahasa sebagai second order mengijinkan kata meja hijau mengemban makna "persidangan". Lapis kedua ini yang disebut konotasi. 
strauss (antropologi), Politik (Voltaire), eksistensialisme (Nietzsche dan Sartre), Rasionalisme (Descartes), juga ilmu-ilmu arkeologi sosialsejarah madzhab analle Perancis. Hal ini tampak dari banyaknya konsep-konsep kaum post-strukturalisme yang diterapkannya ke dalam wilayah kajian Islam. Konsep-konsep seperti korpus, episteme, wacana, dekonstruksi, mitos, logosentrisme, yang tak terpikir dan dipikirkan, parole, aktant, dan lain-lain.

Bagaimana Arkoun menerapkan metode dekosntruksi ${ }^{36}$ terhadap kajian Islam? Arkoun gelisah atas kenyataan ortodoksi Islam yang telah mengendap lama dalam nalar umat Islam. Dalam pandangannya, sumber utama sistem ortodoksi yang rigid itu adalah Al-Qur'an. Oleh sebab itu, langkah pertama yang perlu dibenahi adalah membangun pandangan baru terhadap Al-Qur'an, yang menurut Arkoun selama ini telah disalahgunakan untuk kepentingan ideologi dan politik. Dogma-dogma kaku dalam agama tidak lain lahir karena ketidakmampuan muslim untuk menangkap pesan orisinil dari AlQur'an sebagaimana pada periode awal (periode kenabian) sebagai korpus yang terbuka. ${ }^{37}$

Demi kepentingan ini, Arkoun menggunakan metode dekonstruksi, metode yang digunakan oleh Jacques Derrida. Ia berharap besar untuk mengungkap hal yang belum terungkap, fakta yang tersembunyi yang terselubung dari sejarah dan konsep al-Qur'an. Bagi Arkoun, al Qur'an tunduk pada sejarah. Menurut Leonard Binder,

36 Salah satu tujuan dari metode dekonstruksi adalah menunjukkan ketidakberhasilan upaya penghadiran kebenaran absolut, dan ingin menelanjangi agenda tersembunyi yang mengandung banyak kelemahan dan ketimpangan di balik teks-teks. penerapan dekonstruksi dalam berhadapan dengan teks, adalah: Pertama, mengidentifikasi hirarki oposisional dalam teks, di mana biasanya terlihat peristilahan mana yang diistimewakan secara sistematis dan mana yang tidak. Kedua, oposisioposisi itu dibalik dengan menunjukkan adanya saling ketergantungan di antara yang saling bertentangan atau privilesenya dibalik. Ketiga, memperkenalkan sebuah istilah atau gagasan baru yang ternyata tidak bisa dimasukkan ke dalam kategori oposisional lama. Dengan langkah-langkah semacam ini, pembacaan dekonstruktif berbeda dari pembacaan biasa. Pembacaan biasa selalu mencari makna sebenarnya dari teks, atau bahkan terkadang berusaha menemukan makna yang lebih benar, yang teks itu sendiri barangkali tidak pernah memuatnya. Sedangkan pembacaan dekonstruktif ingin mencari ketidakutuhan atau kegagalan setiap upaya teks menutup diri dengan makna atau kebenaran tunggal. lihat F Budi Hardiman, Filsafat Fragmentaris, 34-35.

${ }^{37}$ Mohammed Arkoun, "Rethinking Islam Today," Annals of the American Academy of Political and Social Science, slam: Enduring Myths and Changing Realities, 588 (2003): 18-39. 
pemikiran Arkoun memperlihatkan kecenderungan dan kekaguman kepada akademisi Perancis beraliran postmodern seperti Paul Ricoer, Michael Foucault, dan Jacques Derrida. Kecenderungan itu tidak lepas dari latar belakang pendidikannya yang dibesarkan di lingkungan pendidikan Perancis.

Selain Arkoun, pemikir yang mengadopsi metode dekonstruksi adalah Muhammad 'Abid al-Jabiri, seorang pemikir Islam kontemporer asal Maroko. Kecenderungan al-Jabiri dalam menggunakan metode dekonstruksi dalam memahami tradisi ArabIslam tidak bisa dilepaskan dari konteks sosio historisnya. Yaitu bahwa para pemikir dekonstruksionis Arab kebanyakan datang dari daerah Maghribi (Maroko, al-Jazair, Tunis dan Libia). Unsur bahasa Perancis warisan kolonialisme yang tersisa di negeri-negeri tersebut menyebabkan kalangan akademisnya lebih menyerap literatur berbahasa Perancis, daripada bahasa-bahasa Eropa lainnya.

Keterikatan intelektual para pemikir Arab Maghribi dengan Perancis bukan hanya sebatas bahasanya, mereka juga terpengaruh oleh gerakan-gerakan pemikiran dan filsafat Perancis kontemporer, khususnya gerakan (post) strukturalisme. Hampir seluruh pemikir Muslim Maghribi yang concern terhadap keislaman dan kearaban adalah penganut paham strukturalisme. Itu karena problem yang mereka hadapi kebetulan sama, yaitu masalah bacaan atas tradisi, baik yang berbentuk teks maupun realitas. Dan menurut mereka, metode yang paling modern dan paling ampuh untuk membaca tradisi (turath) adalah dekonstruksi. ${ }^{38}$

Al-Jabiri menggunakan metode dekonstruksi untuk memhami tradisi Arab-Islam dalam kaitannya dengan modernitas. Ia menawarkan pendekatan obyektivisme (maudhu'iyah) dan rasionalitas (ma'quliyah). Obyektivisme artinya menjadikan tradisi lebih kontekstual dengan dirinya, dan berarti memisahkan dirinya dari kondisi kekinian kita. Proses pemisahan ini harus dilakukan secara dekonstruktif dalam pengertian metodologis, yaitu membebaskan diri dari asumsi-asumsi apriori terhadap tradisi dan keinginan-keinginan masa kini, dengan jalan memisahkan antara subyek pengkaji dan obyek

${ }^{38}$ Yasmeen Samy Daifallah, Political Subjectivity in Contemporary Arab Thought: The Political Theory of Abdullah Laroui, Hassan Hanafi, and Mohamed Abed al-Jabiri (California: California University, 2012), 23. 
yang dikaji. Sedangkan yang dimaksud dengan rasionalitas adalah menjadikan tradisi tersebut lebih kotekstual dengan kondisi kekinian kita. Proses ini adalah merekonstruksi pemikiran baru dengan menghubungkan antara obyek dan subyek kajian. Proses ini dilakukan agar didapatkan pembacaan yang holistik terhadap tradisi. ${ }^{39}$

Selain Arkoun dan al-Jabiri, metode dekonstruksi juga pernah dipinjam oleh Abdullah al-Na'im ${ }^{40}$ dalam memahami teks-teks syari'ah. Dengan semangat dekonstruktif, al-Na'iim mengatakan bahwa, "the public law of Shari'a is not really divine law in the sense that all its specific principles and detailed rules were directly revealed by God to the Prophet Muhammad ("hukum publik syariat bukanlah hukum yang semua prinsip khusus dan aturan rinciannya langsung diwahyukan Allah kepada Nabi Muhammad SAW"). ${ }^{41}$ Ia juga menyatakan bahwa "The techniques through which Shari'a was derived from the devine sources and the ways in which its fundamental concepts and principles were formulated are clearly the product of the intellectual, social, and political processes of Muslim history." ("Teknik-teknik penjabaran syariat dari sumber sucinya dan cara-cara penyusunan konsep dan prinsip fundamentalnya, jelas merupakan produk proses sejarah intelektual, sosial, dan politik umat Islam”)

Pandangan al-Na'im mengundang kontroversinya sendiri terutama ketika penerapan metodenya itu dihadapkan pada teks utama dalam Islam; al-Qur'an dan al-Sunnah. Titik krusialnya adalah ketika teks al-Qur'an dan al-Sunnah berhadapan dengan realitas yang selalu berubah. Teks al-Qur'an dan al-Sunnah ditundukkan pada kehendak waktu dan tempat, pada akal dan kepentingan sesaat. Realitas sosial menjadi standar kebenaran. Oleh sebab itu, apapun adanya jika tidak sesuai dengan "teks realitas sosial" harus diubah dan direinterpretasi. Dengan demikian ayat warisan yang memberi laki-laki lebih banyak dari perempuan harus ditafsir ulang karena realitas sekarang perempuan banyak yang bekerja. Poligami harus dihapuskan karena

${ }^{39}$ al-Jabiri, Al Turath Wal Al-Hadathah, (Beirut: Markaz Dirasat al-Wahdah al-'Arabiyah, 1991), 5.

40 Tentang Abdullah Ahmad an-Na'im lihat Muhammad Dahlan, Abdullah Ahmad Al-Na'im: Epistemologi Hukum Islam (Yogyakarta: Pustaka Pelajar, 2009), 4.

${ }^{41}$ Abdullah Ahmed al-Na'iim, Towards an Islamic Reformation: Civil Liberties, Human Right, and International Law, trans. Ahmad Suaedi (Yogyakarta: LKIS, 2004), 11. 
tidak sesuai dengan budaya masyarakat modern. Hukum hudud dan qisas harus dihapuskan karena tidak sesuai dengan standar International Convention of Human Rights. Dan atas nama realitas juga, wanita Muslimah boleh nikah dengan lelaki non-Muslim. Usul al-fiqh klasik dikritik karena berpaut erat pada teks-teks al-Qur'an dan al-Sunnah. Tanpa mereka sadari, saat ini mereka juga sedang bergantung pada "teks-teks realitas sosial".

Survei terhadap tiga pemikir Islam kontemporer itu, satu sisi menggambarkan 'ketegangan' antara produk-produk posmodernisme. Tetapi pada saat yang sama memberikan tantangan metodologis dalam memahami teks agama dalam kaitannya dengan realitas yang terus berubah.

\section{Penutup}

Posmodernisme ditakdirkan sebagai 'tukang kritik' atas semua bentuk kemapanan, termasuk kemapanan dalam agama. Karya Akbar S Ahmed, ${ }^{42}$ Postmodernism and Islam: Predicament and Promise menjadi salah satu inspirasi. Judul karya ini sudah menyimpan dua makna yang delimatis: antara bahaya dan harapan. Itu artinya, posmodernisme sebagai suatu tata pikir dan nilai harus dibaca secara kritis bagi pembacanya. ${ }^{43}$

Apa yang sesungguhnya dikhawatirkan agama atas 'bahaya' posmodernisme dan apa yang diharapkan darinya? Jika merujuk pada penerjemahan dan analisa Akbar, postmodernisme harus diletakkan dalam posisi yang netral. Postmodernisme, satu sisi mengandung nilainilai negatif bagi kepentingan agama seperti keputusasaan, kepanikan, anarkisme intelektual, peniadaan atas nilai-nilai yang absolut. Tetapi pada saat yang sama ia mengandung nilai-nilai positif seperti keberagaman, kebebasan meneliti dan kemungkinan untuk mengetahui

${ }^{42}$ karya S. Ahmed, Postmodernisme and Islam : Predicament and Promise; lihat juga ulasannya dalam Akbar S. Ahmed, "Observing the Observer", Asian Survey, Vol. 31, No. 3 (Mar., 1991), Pp. 213-231, . Diakses 25 September 2014.

${ }^{43}$ Pembacaan Akbar terhadap respon kaum Muslim di seluruh dunia atas posmodernisme masih terbatas untuk tidak mengatakan dangkal: "The response to postmodernism, to its wit and irony, to its scope and possibilities, is usually incomprehension or anger; it is as if two different peoples were speaking two different languages, representing two different time zones". S. Ahmed, Postmodernisme and Islam : Predicament and Promise, 29. 
dan memahami satu sama lain. Sehingga, pertanyaan yang patut diajukan di sini seperti yang diajukan oleh Akbar dalam konteks keagamaan (Islam) adalah How would Muslim leaders and intellectuals interpret the main features of postmodernism? (bagaimana intelektual dan pemimpin Muslim menginterpretasikan ciri utama posmodernisme?)

Implikasi paling serius atas pandangan relativitas dan devaluasi nilai-nilai adalah keyakinan keagamaan yang ajeg terhadap pemilik otoritas tertinggi dalam agama yaitu Tuhan. Agama tidak lagi berhak mengklaim punya kuasa lebih terhadap sumber-sumber nilai yang dimiliki manusia seperti yang telah di formulasikan oleh para filosof. Agama akan dipahami sebagai sama dengan persepsi manusia sendiri yang tidak mempunyai kebenaran absolut. Oleh sebab itu ia mempunyai status yang kurang lebih sama dengan filsafat. Jika demikian maka agama dalam pemikiran posmodern telah digambarkan dalam bentuk dan sifat yang sangat berbeda dari sebelumnya. ${ }^{44}$

Dengan menginsafi prinsip posmodern akan keberagaman makna, maka sisi-sisi kritis dari postmodern dapat dikontekstualisasikan ke dalam agama, bukan dalam pengertiannya untuk 'menggugat' keberadaan Tuhan, melainkan untuk membantu pemahaman keagamaan agar ia "sholihun li kulli zaman wa makan". Misalnya, pemikiran Michel Foucault. Ia menunjukan keberpihaknnya terhadap wacana-wacana yang tertindas, wacana-wacana yang termarjinalisasikan oleh wacana besar yang mendominasi dan mengontrol, kemudian memunculkan wacana-wacana tandingan berupa "wacana-wacana kecil". Wacana yang dikembangkan mulai dari persoalan tubuh (human body), seksualitas, etnis, kultur, sampai wacana politik global.

${ }^{44}$ Demi merayakan keanekaragaman dan heterogenitas dalam memandang realitas, posmodernisme menolak segala klaim universal epistemologis dan klaim tunggal atas fondasi epistemologis termasuk fondasi metafisika. Ia menolak dua detereminasi. Pertama, determinasi retrospektif, yaitu segala dogma atau prinsip yang berasal dari sumber-sumber metafisik atau ilahiah, dengan memandang kebenaran yang dibawanya sebagai relative. Kedua, determinasi pprospektif berupa kepastian teleologis tentang masa depan dunia dan umat manusia (seperti surge, akhirat). Ia bukan tidak percaya pada metafisika dan teleologi, melainkan menangguhkan kepastian epsitemologisnya. Yasraf Amir Piliang, Bayang-Bayang Tuhan, Agama Dan Imajinasi (Bandung: Mizan, 2011), 41-42. 
Dalam perjalanan berikutnya gerakan postmodernisme lebih cenderung mengambil kembali paradigma pramodern dengan menampilkan diri seperti gerakan kembali ke alam (back to nature), kembali ke adat tardisi (back to culture), dan kembali kepada kearifan tradisional. [.]

\section{Referensi}

Abdul 'Dubbun' Hakim. "Diskursus Filosofis Modernitas, Debat Jurgen Habermas Dan Jacques Derrida." In Majalah Filsafat Diryakara, 2nd ed., xxv:63. Jakarta: Seksi Publikasi Senat Mahasiswa, 2001.

Agus, Firmansyah. Dekonstruksi Spiritual, Merayakan Ragam Wajah Spiritual. Yogyakarta: Jalasutra, 2002.

Ahmed, Akbar S. Postmodernism and Islam: Predicament and Promise. London \& New York: Routledge, 1992.

Akbar S. Ahmed. "Observing the Observer", Asian Survey, Vol. 31, No. 3 (Mar., 1991), Pp. 213-231, . Diakses 25 September 2014." Asian Survey 31, no. 3 (1991): 213-31.

al-Jabiri. Al Turath Wal Al-Hadathah, Beirut: Markaz Dirasat alWahdah al-'Arabiyah, 1991.

Bat, Mieke, and Hent de Vries. Counterpath Traveling with Jacques Derrida. Calivornia: Stanford University Press, 2004.

Bracher, Mark, and Jacques Lacan. Diskursus, Dan Perubahan Sosial: Pengantar Kritik Budaya Psikoanalisis. Yogyakarta: Jalasutra, 2009.

Cox, Harvey. Religion and the Secular City: Toward a Postmodernism Theology. New York: Simon and Shuster, 1984.

Dahlan, Muhammad. Abdullah Ahmad Al-Na'im: Epistemologi Hukum Islam. Yogyakarta: Pustaka Pelajar, 2009.

Daifallah, Yasmeen Samy. Political Subjectivity in Contemporary Arab Thought: The Political Theory of Abdullah Laroui, Hassan Hanafi, and Mohamed Abed al-Jabiri. California: California University, 2012.

F Budi Hardiman. Filsafat Fragmentaris. Yogyakarta: Kanisius, 2007. Finkielkraut. The Defeat of the Mind. New York: Columbia University Press, 1995. 
Foucault, Michel. "Of Other Spaces, Heterotopias," n.d. http://foucault.info/documents/heterotopia/foucault.heterotopi a.en.html.

Gellner, Ernest. Postmodernism, Reason and Religion. London: Routledge, 1992.

Gianni Vattimo. The End of Modernity. Polity Press in Association with B. Blackwell, 1988.

Griffin, David. God and Religion in Postmodern World. Albany: N.Y. State University of New York Press, 1989.

Griffin, David Ray, and Huston Smith. Primordial Truth and Postmodern Theology. New York: State University of New York Press, 1989.

Habermas, Jurgen. The Philosophical Discourse of Modernity. Blackwell Publisher, 1987.

Habermas, Jürgen, and Seyla Ben-Habib. "Modernity versus Postmodernity', New German Critique.” Winter, special Issue on Modernism, no. 22 (1981): 3-14.

Heidigger, Martin. Being and Time. Oxford: Basil Blacwell, 1962.

iim, Abdullah Ahmed al-Na'. Towards an Islamic Reformation: Civil

Liberties, Human Right, and International Law. Translated by Ahmad Suaedi. Yogyakarta: LKIS, 2004.

Lubis, Akhyar Yusuf. Postmodernisme, Teori Dan Praktek. Jakarta: Rajawali Press, 2014.

Lyotard, Jean-Francois. Postmodern Condition: A Report on Knowledge. Manchester: Manchester University Press, 1984.

Mikics, David. Who Was Jacques Derrida?: An Intellectual Biography. New Heven \& London: Yale University Press, 1961.

Mohammed Arkoun. "Rethinking Islam Today." Annals of the American Academy of Political and Social Science, slam: Enduring Myths and Changing Realities, 588 (2003): 18-39.

Nietzsche. The Will To Power. New York: Random House, 1968.

Norris, Christoper. Membongkar Teori Dekonstruksi Jacques Derrida. Yogyakarta: Ar-Ruzz Media, 2008.

Owen, David. Maturity and Modernity. London: Routledge, 1994.

Piliang, Yasraf Amir. Bayang-Bayang Tuhan, Agama Dan Imajinasi. Bandung: Mizan, 2011.

Ritzer, George. Postmodern Social Theory. United States America, 1976.

Roxanne L. EubenSource. Premodern, Antimodern or Postmodern? Islamic and Western Critiques of Modernity", The Review of 
Politics, Vol. 59, No. 3,. Diakses, 25 September 2014. Vol. 59. 3. The Review of Politics, 2014. http://www.jstor.org/stable/1408547.

S. Ahmed, Akbar. Postmodernisme and Islam: Predicament and Promise. London \& New York: Routledge, 1992.

Sahal, Ahmad. Agama Dan Tantangan Posmodernisme. Jakarta: Islamika, 1993.

Smith, Huston. Beyond The Post-Modern Mind. Wheaton, Illinois, USA: The Theosophical Publishing House, 1989.

Sugiharto, Bambang. Postmodernisme Tantangan Bagi Filsafat, n.d. Trilling, James. "A Modernist's Critique of Postmodernism Vol. 9, No. 3 (Spring, 1996), Pp. 353-37,." International Journal of Politics, Culture, and Society, 3, 9 (1996). http://www.jstor.org/stable/20019842. Diakses. 